\title{
Linkages between hydrological drought, climate indices and human activities: a case study in the Columbia River basin
}

\author{
Shengzhi Huang, ${ }^{\text {a* }}$ Qiang Huang, ${ }^{\mathrm{a}}$ Jianxia Chang ${ }^{\mathrm{a}}$ and Guoyong Leng ${ }^{\mathrm{b}}$ \\ a State Key Laboratory Base of Eco-Hydraulic Engineering in Arid Area, Xi'an University of Technology, China \\ ${ }^{\mathrm{b}}$ Institute of Geographic Sciences and Natural Resources Research, Chinese Academy of Sciences, Beijing, China
}

\begin{abstract}
It is of great importance to investigate links between hydrological drought and climate indices, which helps to further reveal the cause of hydrological drought from a perspective of climate change, thus helping guiding future drought prediction and control. For a case study in the Columbia River basin, the Standardized Streamflow Index (SSI) was employed to characterize hydrological drought. The heuristic segmentation method was applied to identify change points of annual streamflow series spanning 1960-2012 in the Columbia River basin, and the cross-wavelet analysis was utilized to reveal the correlations between monthly climate indices and SSI. The primary results are as following: (1) monthly SSI has a statistically significantly increasing trend in November and December and a noticeably decreasing trend in June and July in the main stream of the basin; (2) generally, hydrological drought risk in this basin is high, and that in the Snake River is higher than the main stream of the Columbia River; (3) El Niño Southern Oscillation (ENSO) and Arctic Oscillation (AO) play a major role in affecting hydrological drought in the Columbia River basin, and ENSO index mainly affects SSI at a relatively short time scale (2-7 years), while AO primarily impacts SSI at a relatively long time scale (more than 10 years); (4) anthropogenic activities intensify hydrological drought in the Columbia River basin, and they primarily influence the linkages between climate indices and hydrological drought at intra-annual scale (less than 12 months), however, which do not change the basic pattern of their correlations.
\end{abstract}

KEY WORDS hydrological drought; Standardized Streamflow Index; climate indices; cross-wavelet analysis; anthropogenic activities; Columbia River basin

Received 15 January 2015; Revised 17 March 2015; Accepted 18 March 2015

\section{Introduction}

Drought is a natural climate phenomenon that usually begins with the deficit of precipitation, leading to soil moisture shortage because of evapotranspiration, and river flow decrease, thereby unfavourably impacting plant growth and human activities (Li et al., 2013). Drought is one of the most costly reoccurring natural hazards, causing greatly adverse economic, ecological, and social influences. As Henderson and Kauffman (2012) pointed out that the 2012 Midwestern US drought caused \$12 billion in damages primarily coming from agricultural losses. It should be noted here that the global environment and climate have witnessed a remarkable change over the past century in which global warming is one of the most obvious characteristics. The global warming intensifies global hydrological cycle and leads to more frequent extreme events such as droughts and floods on a global scale (Kunkel, 2003; Roy and Balling, 2004; Huang et al., 2014a; Ma et al., 2014; Li et al., 2015). Hence, the frequency of drought is expected to increase under the backdrop of global warming (Christensen and

\footnotetext{
* Correspondence to: S. Huang, State Key Laboratory Base of Eco-Hydraulic Engineering in Arid Area, Xi' an University of Technology, Xi'an 710048, China. E-mail: huangshengzhi7788@126.com
}

Christensen, 2004). Therefore, it is of great importance to increase the knowledge of drought events trends, which helps to improve adaptive capabilities to climatic change (Osorio and Galiano, 2012).

Droughts can be classified into four types: meteorological, agricultural, hydrological and socioeconomic droughts with respect to the shortages of precipitation, runoff, soil moisture, as well as water availability, respectively (American Meteorological Society (AMS), 2004). Amongst various types of droughts, hydrological drought is the most important, largely owing to the high dependence of urban, industrial and agricultural supply and hydropower generation on surface water resources (Vasiliades et al., 2011). Nowadays, the frequent method used for investigating droughts is to establish different drought indices, and subsequently the objective quantification of various drought characteristics in terms of duration, magnitude, intensity and spatial extent was carried out (Heim, 2002; Mishra and Singh, 2010). Generally, existing indices for monitoring hydrological drought such as Surface Water Supply Index or Palmer Hydrological Drought Index are intensive computation and data demanding (Talaee et al., 2014). This study focused on hydrologic drought based on Standardized Streamflow Index (SSI). The SSI is highly similar to Standardized Precipitation Index (SPI) frequently applied to 
meteorological drought analysis. The SSI, therefore, has the advantages of simplicity and effectiveness compared with other hydrological drought indices and is the most commonly utilized method in drought studies (Modarres, 2007).

The distribution and severity of hydrological drought are greatly irregular in temporal and spatial dimensions. Climate indices such as the North Atlantic Oscillation (NAO) and El Niño Southern Oscillation (ENSO) can account for this variability to a certain extent (Talaee et al., 2014). Stefan et al. (2004) found that the persistent meteorological and hydrological drought conditions in the southern part of Romania were closely related to the persistent positive phase of NAO. Stahl and Demuth (1999) stated that the hydrological drought in southern Germany was strongly linked to several high-pressure and anticyclonic atmospheric circulation patterns. Xu et al. (2004) found that linkage between ENSO and precipitation anomalies was statistically significant in the south and middle portion of South-east Asia and the Pacific region, but significant link was not identified in the northern part. Vicente-Serrano (2005) indicated that the spatial discrepancies in drought conditions during extreme phases of the Southern Oscillation (SO) were obvious. All of the previous studies successfully found the correlations between climate indices and the hydro-meteorological variables of their study area. However, because the methods used in their studies were focused on correlation analysis, they only can reveal general correlation between climate indices and local hydrological processes, whereas the evolution of their correlations is not comprehensively revealed, which is very important to further understanding the process of climate change and their impacts on hydrological response, thus helping to improve the adaptive capacity to climate change and the efficiency of local water resources management. Therefore, it is very essential to investigate the evolution of the correlations between climate indices and local hydrological drought. The cross-wavelet analysis is a new technique based on the cross-spectrum analysis and wavelet transform. It can preferably reveal the detailed linkages of two specific time series in time and frequency domains. Thus, the cross-wavelet analysis can be used to investigate the evolution of their correlations between the two time series (Hudgins and Huang, 1996; Torrence and Compo, 1998). Hence, the cross-wavelet analysis was utilized in this study to reveal the detailed correlations between climate indices and hydrological drought and their evolution.

Considerable evidences show a strong linkage between climate indices and the hydro-meteorological variables of the Middle East (Ghasemi and Khalili, 2006; Marcella and Eltahir, 2008; Sabziparvar et al., 2011). However, there is little evidence concerning influences of climate indices on hydrological drought in the Columbia River basin. The Columbia River is the fourth largest in the United States and the largest river on the Pacific Coast of North America in terms of runoff volume (Kammerer, 1990). It is the home to a large number of endangered or threatened aquatic species. In addition, supplies irrigation, navigation and hydroelectricity heavily rely on it. A large amount of its water is derived from the Rocky Mountain headwaters. Therefore, the occurrence of hydrological droughts has a great effect on local endangered aquatic species, irrigation, navigation and hydroelectricity. Thus, it is necessary to investigate the risk of hydrological droughts and their linkages with climate indices, which is the major motivation of this study. Furthermore, human activities (e.g. reservoir regulation, navigational development, water withdrawal and so on) in the Columbia River basin are intensifying (Naik and Jay, 2005), which probably have some impacts on the correlations between climate indices and hydrological droughts. How do human activities influence their correlations merits a further investigation due to its contribution to helping revealing local hydrological response to climate change and intensifying human activities. Therefore, the impact of human activities on the correlations between climate indices and hydrological drought in the Columbia River basin was investigated in this study, and it is another motivation of this study.

Located in the Northwest Pacific, the climate of the Columbia River basin is affected by ENSO, the Pacific Decadal Oscillation (PDO) and Atlantic Multidecadal Oscillation (AMO) (Kam et al., 2014). Additionally, the Arctic Oscillation (AO) is a very important part of climate change in the Northern Hemisphere and has a strong impact on the climate of middle and high latitude regions (Hudgins and Huang, 1996). Therefore, the ENSO, AMO, PDO and AO indices were utilized to comprehensively reveal the detailed correlations between climate indices and hydrological droughts in the Columbia River basin in this study. The primary objectives of this study are to (1) obtain the spatial-temporal change characteristics of hydrological droughts in the Columbia River basin; (2) reveal the detailed correlations between climate indices and hydrological drought and their evolution and (iii) investigate the influence of human activities on the correlation between climate indices and hydrological drought.

\section{Study area and data}

\subsection{Study area}

The Columbia River basin is divided into two parts by the north-south-trending Cascade Mountain Range, namely, the western sub-basin with area of $46650 \mathrm{~km}^{2}$ where the Willamette River is the largest drainage and the interior sub-basin covering $613830 \mathrm{~km}^{2}$ which lies in east of the Cascade Range (Naik and Jay, 2005). The interior sub-basin primarily consists of the Upper Columbia and the Snake River, and 97\% of the total interior sub-basin streamflow is gauged at Dalles station (Naik and Jay, 2005). Annual precipitation of the Columbia River basin increases from east to west, ranging from $<250 \mathrm{~mm}_{\text {year }}{ }^{-1}$ over the Columbia plateau and the Snake River basin to $>2550 \mathrm{~mm}_{\text {year }}{ }^{-1}$ in the coastal area. Although the western sub-basin accounts for only $7 \%$ of the basin area, it contributes approximately $25 \%$ of the total runoff. Streamflow in the western sub-basin occurs mostly coming from winter precipitation, from November to March. 


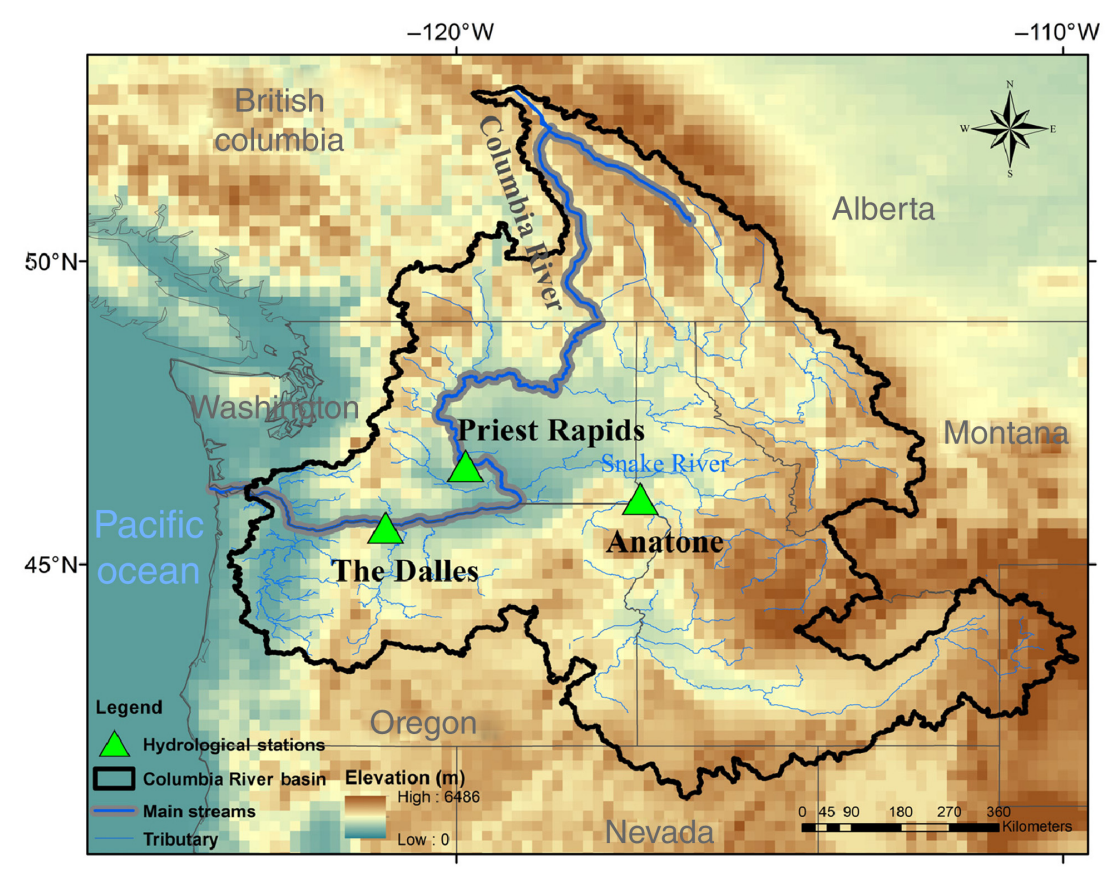

Figure 1. The Columbia River basin and the related hydrological stations.

Conversely, the flow of the interior sub-basin mostly occurs during the spring snowmelt, from April to July. Because the interior sub-basin has a large drainage area, it encompasses remarkable precipitation variations (Naik and Jay, 2005).

\subsection{Data}

In view of their control areas and typical climate type, Dalles, Priest Rapids and Anatone hydrological stations are selected in this study. This study used monthly streamflow records covering 1960-2012 at the three hydrological stations whose locations are shown in Figure 1. Dalles station is located in the downstream of the Columbia River, while Priest Rapids located in the main stream lie in the midstream of the river and Anatone station is located in the middle reaches of the Snake River. Note that Priest Rapids primarily controls drainage basin of rich rain, whilst Anatone mainly controls drainage basin of rare rain. It is of great importance to investigate the linkages between hydrological drought and climate indices in various climate zones, which help to reveal the different hydrological response under the background of global climate change. Monthly AMO, ENSO, PDO and AO data covering 1960-2005 were also applied in this study. The monthly streamflow data were acquired from US Geological Survey (USGS) (http://waterdata.usgs.gov/wa/nwis/current/?type=flow). The monthly AMO and PDO time series covering 1960-2005 were obtained from the National Oceanic and Atmospheric Administration (NOAA) Earth System Research Laboratory (http://www.esrl.noaa.gov/psd/data/ correlation/amon.us.long.data) and the Tokyo Climate Center (http://ds.data.jma.go.jp/tcc/tcc/products/elnino/ decadal/pdo.html), respectively. Regarding ENSO, we use Nino 3.4 Index derived from the NOAA Earth System
Research Laboratory (http://www.esrl.noaa.gov/psd/data/ correlation/nina34.data). For AO, its monthly data covering 1960-2005 were obtained from the NOAA National Climatic Data Center (http://www.ncdc.noaa.gov/ teleconnections/ao.php). Additionally, in order to investigate the influence of human activities on the correlation between hydrological drought and climate indices, the naturalized monthly streamflow data covering 1960-2005 of Dalles, Anatone and Priest Rapids stations obtained from the Surface Hydrology Group, University of Washington (http://www.hydro.washington.edu/2860) were adopted, which were simulated by the Variable Infiltration Capacity (VIC) hydrologic model. The naturalized streamflow simulated by the VIC model is bias-adjusted based on naturalized or modified flow that is available at a number of locations in the Columbia River basin (Flightner, 2008). A bias correction procedure based on quantile mapping techniques is adopted to produce the monthly time step streamflow simulation for the site which has naturalized or modified flow. These techniques remove systematic biases in the simulations of routed streamflow to produce products that very closely match the long-term statistics and time series behaviour of a natural or modified flow dataset for a particular site. These bias-corrected values are often very useful in water planning studies, especially for the purpose of providing inputs to reservoir operations models that are calibrated on a particular naturalized flow dataset (e.g. Hamlet et al., 2010; Vano et al., 2010). These approaches are also very useful for avoiding biases in the streamflow simulations that result from systematic errors in gridded precipitation or temperature data (the key inputs to the hydrologic models) (Hamlet et al., 2010). Therefore, we used the bias-adjusted VIC runoff data to analyse the impact of anthropogenic activities on the correlation between SSI and climate indices in this study. 


\section{Methodologies}

\subsection{The heuristic segmentation method}

Existing statistical test methods including the rank sum test, sliding $F$ test, sliding $T$-test and Mann-Kendell test are frequently applied to detect change point of time series. All of them are on a basis of the assumption that sample series is linear and smooth. However, hydrological time series shows greatly nonlinear characteristic because of the high variability of hydrological process. Hence, these approaches are difficult to identify real change points. Thus, the heuristic segmentation method which is based on the thought of sliding $T$-test and modified to detect change point of nonlinear time series was introduced to detect change point of annual streamflow series in the Columbia River basin. It was proposed by Pedro et al. (2001). A sliding pointer is moved step-by-step from left to right along the whole time series in order to divide the non-stationary time series into several stationary segments (Pedro et al., 2001). The averages of the subsets in the two sides $\left(\mu_{1}\right.$ and $\left.\mu_{2}\right)$ are then computed. For two Gaussian-distributed random series, their difference between the mean values of the two series at a given statistical significance level is assessed by the Student's $t$-test statistic expressed as following:

$$
t=\left|\frac{\mu_{1}-\mu_{2}}{S_{\mathrm{D}}}\right|
$$

where

$$
S_{\mathrm{D}}=\left(\frac{\left(N_{1}-1\right) s_{1}^{2}+\left(N_{2}-1\right) s_{2}^{2}}{N_{1}+N_{2}-2}\right)^{1 / 2}\left(\frac{1}{N_{1}}+\frac{1}{N_{2}}\right)^{1 / 2}
$$

denotes the pooled variance, $s_{1}$ and $s_{2}$ are the standard deviations of the two series, $N_{1}$ and $N_{2}$ represent the number of points from the two series. By moving the pointer along the given time series step-by-step, the statistic $t$ is computed to evaluate the difference between the mean values of the left and right sides time series. A larger $t$ means that the averages of the two time series are expected to be more different. The largest $t$ value is seen as a good indicator for the cut point. Then, the statistical significance $P\left(t_{\max }\right)$ is calculated. Note that $P\left(t_{\max }\right)$ is not the standard Student's $t$-test because the series are not independent and cannot be gained in a closed analytical form. Therefore, $P\left(t_{\max }\right)$ is calculated approximately as follows:

$$
P\left(t_{\max }\right) \approx\left\{1-I_{\left[v /\left(v+t_{\max }^{2}\right)\right]}(\delta v, \delta)\right\}^{\eta}
$$

where $\eta=4.19 \ln N-11.54$ and $\delta=0.40$ gained from the Monte Carlo simulations. $N$ is the number of the whole time series, $v=N-2$, and $I_{x}(a, b)$ is an incomplete beta function. If the difference between the mean values is not statistically significant at $95 \%$ significance level, the time series will be not split. Conversely, the time series will be divided into two sub-series. After original time series is split, the iteration of the above procedures on each new sub-series will continue until the obtained significant value is smaller than the threshold or the length of the gained subseries is less than the presupposed minimum length $\left(\ell_{0}\right)$.

\subsection{Standardized Streamflow Index}

The SSI was employed to characterize hydrological drought in this study. It is similar to SPI, and thus it also has the characteristics of simplicity and effectiveness. Differently, for SPI, gamma distribution is commonly utilized to fit monthly precipitation (McKee et al., 1993), whilst Pearson III distribution is frequently used to fit monthly runoff series during the calculation of SSI (Vicente-Serrano et al., 2012). Thus, Pearson III distribution was applied to fit monthly runoff at Dalles, Priest Rapids and Anatone stations. The parameters of the Pearson III distribution were assessed by the L-moment method (Hosking, 1990). Because many previous papers introduced the detailed procedures of calculating SSI, they were therefore omitted in this study. Readers can refer to Li et al. (2013) for the detailed procedures.

\subsection{Identification of drought event}

Once the hydrological drought index based on streamflow data series is calculated, taking some criteria to detect drought events is necessary. Severity, duration and intensity are three important drought features. Drought duration is the number of months when SSI is less than a specific threshold, while drought severity is defined as the total deficits of SSI values those are continuously below the threshold. Drought intensity is the ratio of drought severity to drought duration. These features are interrelated, and any two of them are enough to completely depict a single drought event (Sadeghipour and Dracup, 1985), therefore, drought severity and drought duration were selected in this study (Huang et al., 2014b). Because -0.8 is frequently chosen as the moderate drought threshold in hydrological drought analysis (Hao and AghaKouchak, 2013), -8 was selected as the moderate drought threshold in analysing hydrologic drought in this study. Additionally, considering the persistent nature of drought, the relevant drought duration is defined as a time period more than 3 months (Mo, 2010).

\subsection{The cross-wavelet analysis}

The cross-wavelet transform is a new technique based on the cross-spectrum analysis and wavelet transform. It can preferably reveal the detailed correlations between two particular time series in both time and frequency domains (Torrence and Compo, 1998; Grinsted et al., 2004). The cross-wavelet transform of two given time series $x_{n}$ and $y_{n}$ can be expressed as $W^{X Y}=W^{X} W^{Y^{*}}$, in which * stands for their complex conjugation. The cross-wavelet power is expressed as $\left|W^{X Y}\right|$. The complex argument $\arg \left(W^{x y}\right)$ can be regarded as the local relative phase between $x_{n}$ and $y_{n}$ in both time and frequency domains. The theoretical distribution of the cross-wavelet power of the two time series with their background power spectra $P_{k}^{X}$ and $P_{k}^{Y}$ refers to 
Table 1. The MMK statistics of monthly SSI and annual streamflow series at the three stations.

\begin{tabular}{|c|c|c|c|c|c|c|c|c|c|c|c|c|c|}
\hline Stations & January & February & March & April & May & June & July & August & September & October & November & December & Annual \\
\hline Priest Rapids & $3 * *$ & 1.4 & 0.5 & 0.4 & -1.3 & $-2.2 *$ & $-2.5^{*}$ & -1.2 & -0.8 & 0.7 & $3.3^{* *}$ & $4.1 * *$ & -1.4 \\
\hline Anatone & $-2.2 *$ & $-2.2 *$ & -0.4 & 0.2 & 0.4 & -0.7 & 0.1 & -0.3 & -1.1 & $-3.0 * *$ & $-4.6^{* *}$ & $-3.3^{* * *}$ & -0.8 \\
\hline Dalles & 1.8 & -0.1 & 0.5 & 0.7 & -1 & $-2.5^{*}$ & $-2.4^{*}$ & -0.4 & -0.7 & -0.9 & $2.1^{*}$ & 1.4 & -1.3 \\
\hline
\end{tabular}

*Significant at $95 \%$ significance level; **significant at $99 \%$ significance level.

Torrence and Compo (1998) expressed as following:

$$
D\left(\frac{\left|W_{n}^{X}(s) W_{n}^{Y *}(s)\right|}{\sigma_{X} \sigma_{Y}}<p\right)=\frac{Z_{v}(p)}{v} \sqrt{P_{k}^{X} P_{k}^{Y}}
$$

where $Z_{v}(p)$ is the confidence level related to the probability $p$ for a probability distribution function defined by the square root of the result of two $\chi^{2}$ distributions (Grinsted et al., 2004). The related codes can be downloaded freely on the following website: http://www.pol.ac.uk/ home/research/waveletcoherence/.

\section{Results and discussions}

\subsection{Trends of monthly SSI and annual runoff}

The result of the Mann-Kendall (MK) trend test method recommended by the World Meteorological Organization (WMO) is impacted by the persistence of time series. Therefore, Hamed and Rao (1998) made an improvement on the initial MK test method through considering the lag-i autocorrelation to avoid the persistence. Daufresne et al. (2009) indicated that the modified Mann-Kendall (MMK) test was robust in terms of capturing the trends of hydro-meteorological series. Thus, the MMK trend test method was utilized to capture the trends of monthly SSI values and annual streamflow at Dalles, Anatone and Priest Rapids stations. Their statistics of MMK at the three stations are exhibited in Table 1.

It can be observed from Table 1 that the monthly SSI at Priest Rapids station has a statistically significantly increasing trend in January, November and December at 99\% significance level and a strikingly decreasing trend in June and July at $95 \%$ significance level. For the monthly SSI at Dalles station, it shows a statistically significantly increasing trend in November at $95 \%$ significance level and a statistically significantly deceasing trend in June and July at $95 \%$ significance level. With regards to the monthly SSI at Anatone station, it has a statically significantly decreasing trend in January, February, October, November and December. Among these months, SSI in October, November and December has a statically decreasing which is significant at $99 \%$ confident level. The obviously drying trend in the Snake River easily triggers drought, and relevant department should draw high attention to this. Generally, the monthly SSI values in the main stream of the Columbia River basin have a statistically significantly increasing trend in November and December and a statistically significantly decreasing trend in June and July. The case of the Snake River is different. It has a statistically significantly decreasing trend in January, February, October, November and December, implying that different climate zones have different hydrological response to global climate change. Comparatively, the trend at Priest Rapid station is more striking than that at Dalles station. Furthermore, the annual streamflow at the three stations shows a non-statistically significantly decreasing trend. Overall, the SSI values in the Columbia River basin have a remarkable intra-annual variation characteristic.

\subsection{Identification of change points of annual streamflow series}

The Fourth Assessment Report of the Intergovernmental Panel on Climate Change (IPCC) claimed that global mean temperature had increased by approximately $0.74^{\circ} \mathrm{C}$ (IPCC, 2007) during the latest century. The increasing surface temperature leads to higher evaporation rates and facilitates the atmosphere to transport larger amount of water vapour, thereby resulting in an accelerated hydrological cycle and possibly changing local hydrological processes (Menzel and Bürger, 2002; Wang et al., 2013). Thus, the annual streamflow series in the Columbia River basin may have change points under the background of climate change and intensifying human activities. Identification of change points is an important procedure to judge whether local hydrologic regime is changed, which is of great importance to local water resources planning and management. Therefore, the heuristic segmentation method outlined in Section 3.2 was applied to detect change points of annual streamflow series at the three stations in the Columbia River basin. The threshold $P_{0}$ was selected as 0.95 and $\ell_{0}$ was set to 25 in this study. The identification results of change points at the three stations are illustrated in Figure 2.

It can be obviously observed from Figure 2 that the annual streamflow series of all the stations have no change points due to the probability of the largest $T$ at all the stations is less than $P_{0}$, implying that the hydrologic regime of the Columbia River basin keeps unchanged to a great extent under the backdrop of climate change and human activities, albeit the SSI values in the Columbia River basin have a noticeable intra-annual variation characteristic.

\subsection{Statistical characteristic of historical hydrological} droughts based on observed runoff

Drought duration and severity were chosen to depict drought event in this study. According to the method of identification of drought event introduced in Section 3.4, the statistical results of historical hydrological droughts 


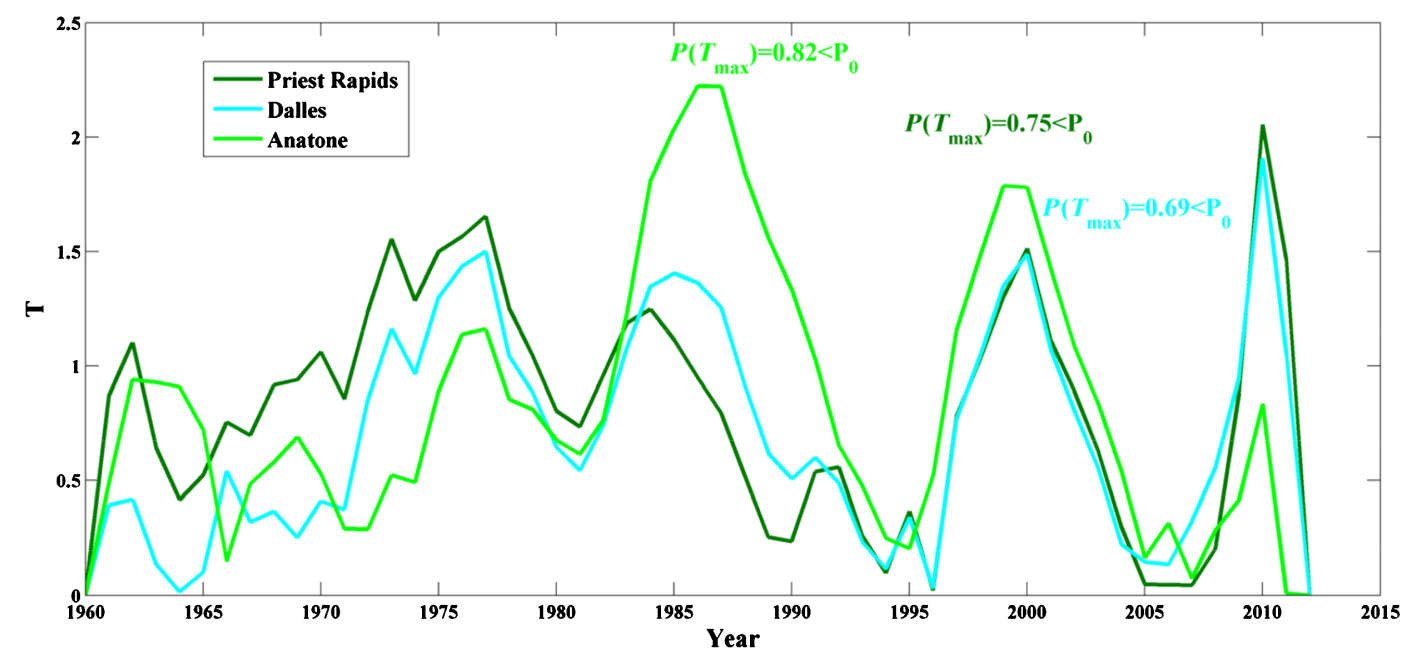

Figure 2. The identification results of change points of annual observed runoff at the three stations in the Columbia River basin.

Table 2. The statistical results of historical hydrological droughts based on observed runoff at the three stations.

\begin{tabular}{|c|c|c|c|c|c|}
\hline \multicolumn{2}{|c|}{ Dalles } & \multicolumn{2}{|c|}{ Priest Rapids } & \multicolumn{2}{|c|}{ Anatone } \\
\hline Duration & Severity & Duration & Severity & Duration & Severity \\
\hline 3 & 3.28 & 3 & 3.8 & 5 & 5.27 \\
\hline 4 & 6.35 & 4 & 6.65 & 5 & 5.16 \\
\hline 7 & 11.17 & 7 & 12.42 & 8 & 13.83 \\
\hline 7 & 12.37 & 7 & 7.44 & 7 & 8.12 \\
\hline 6 & 6.67 & 8 & 14.11 & 10 & 13.19 \\
\hline 7 & 7.81 & 3 & 3.73 & 3 & 2.74 \\
\hline 4 & 5.89 & 7 & 8.6 & 4 & 3.95 \\
\hline 7 & 12.3 & 5 & 6.57 & 6 & 6.77 \\
\hline 4 & 4.46 & 3 & 3.42 & 17 & 23.68 \\
\hline 3 & 4.12 & 3 & 4.57 & 5 & 5.76 \\
\hline 3 & 4.14 & 5 & 7.85 & 5 & 7.18 \\
\hline 7 & 8.49 & 3 & 3.2 & 14 & 18.52 \\
\hline 3 & 4.2 & 4 & 5.59 & 4 & 5.77 \\
\hline 7 & 7.69 & 3 & 3.21 & 5 & 6.84 \\
\hline 4 & 3.87 & 5 & 5.8 & 7 & 8.56 \\
\hline 5 & 7.86 & 3 & 4.56 & 3 & 3.66 \\
\hline 12 & 18.54 & 4 & 4.66 & & \\
\hline 3 & 2.92 & 8 & 13.51 & & \\
\hline \multicolumn{6}{|l|}{ Sum } \\
\hline 96 & 132.13 & 85 & 119.69 & 108 & 139 \\
\hline
\end{tabular}

based on observed runoff at the three stations are shown in Table 2 .

It can be seen from Table 2 that the occurrence of moderate drought events at the three stations ranges from 16 to 18 , implying that droughts frequently occur in the Columbia River basin. The Dalles station has a drought event lasting for 1 year. For Priest Rapids station, there exist no drought events with duration more than one year. Regarding Anatone station, two drought events last more than 12 months. Although the number of drought events at Dalles and Priest Rapids is larger than that of Anatone station, their total drought duration and severity are less than those of Anatone station, indicating that drought risk in the Snake River is higher than the main stream in the Columbia River. This finding further verifies that the
Snake River basin is a drought-prone area, and some local drought mitigation measures should be taken in advance. In view of the severity of droughts in the Columbia River basin, the detailed information of the three worst droughts at the three stations is displayed in Table 3. Overall, the hydrological drought risk in the Columbia River basin is high. Therefore, it is necessary to investigate the detailed linkages between SSI and climate indices. These linkages play an important role in influencing regional climate and hydrological drought in the Columbia River basin.

\subsection{The links between climate indices and SSI and their evolutions}

It is important to reveal the correlations between climate indices and SSI, which helps to further understand the cause of hydrological drought from a perspective of climate change. Therefore, the cross-wavelet analysis was utilized to investigate the correlations between monthly SSI and monthly AMO, ENSO, PDO and AO indices covering 1960-2005 at Dalles, Priest Rapids and Anatone stations, respectively, in the Columbia River basin. The cross-wavelet transforms between monthly SSI based on observed runoff and climate indices at Dalles and Anatone stations are illustrated in Figures 3 and 4, respectively.

It can be obviously observed from Figure 3 that AMO and PDO indices have a weak influence on SSI series based on observed streamflow in the Columbia River Basin. Comparatively, ENSO and AO have a strong impact on SSI series. Figure 3(b) indicates that ENSO index has a significant positive correlation with SSI based on observed runoff with an 8-15 month signal during 1960-1969 and a 16-46 month signal during 1967-1979. The mean phase of the significant regions is about $23^{\circ}$, implying that the ENSO index is leading SSI nearly 0.7 months. Moreover, ENSO index has a significant negative linkage with SSI based on observed streamflow with a 20-32 month signal during 1963-1967 and a 32-48 month signal during 1995-2000, which is consistent with ENSO periodicity of 2-7 years (Dash et al., 2013). The mean phase of the significant regions is about $87^{\circ}$, implying that the ENSO 
Table 3. The detailed information of the three worst droughts at the three stations.

\begin{tabular}{|c|c|c|c|c|c|}
\hline \multicolumn{2}{|l|}{ Dalles } & \multicolumn{2}{|l|}{ Priest Rapids } & \multicolumn{2}{|l|}{ Anatone } \\
\hline Duration & Severity & Duration & Severity & Duration & Severity \\
\hline October 1963-April 1964 & 12.37 & September 1962-March 1963 & 12.42 & January 1988-October 1988 & 13.19 \\
\hline February 1977-August 1977 & 12.3 & September 1963-April 1964 & 14.11 & October 1991-February 1993 & 23.68 \\
\hline January 2001-December 2001 & 18.54 & March 2001-October 2001 & 13.51 & January 2001-December 2001 & 18.91 \\
\hline
\end{tabular}
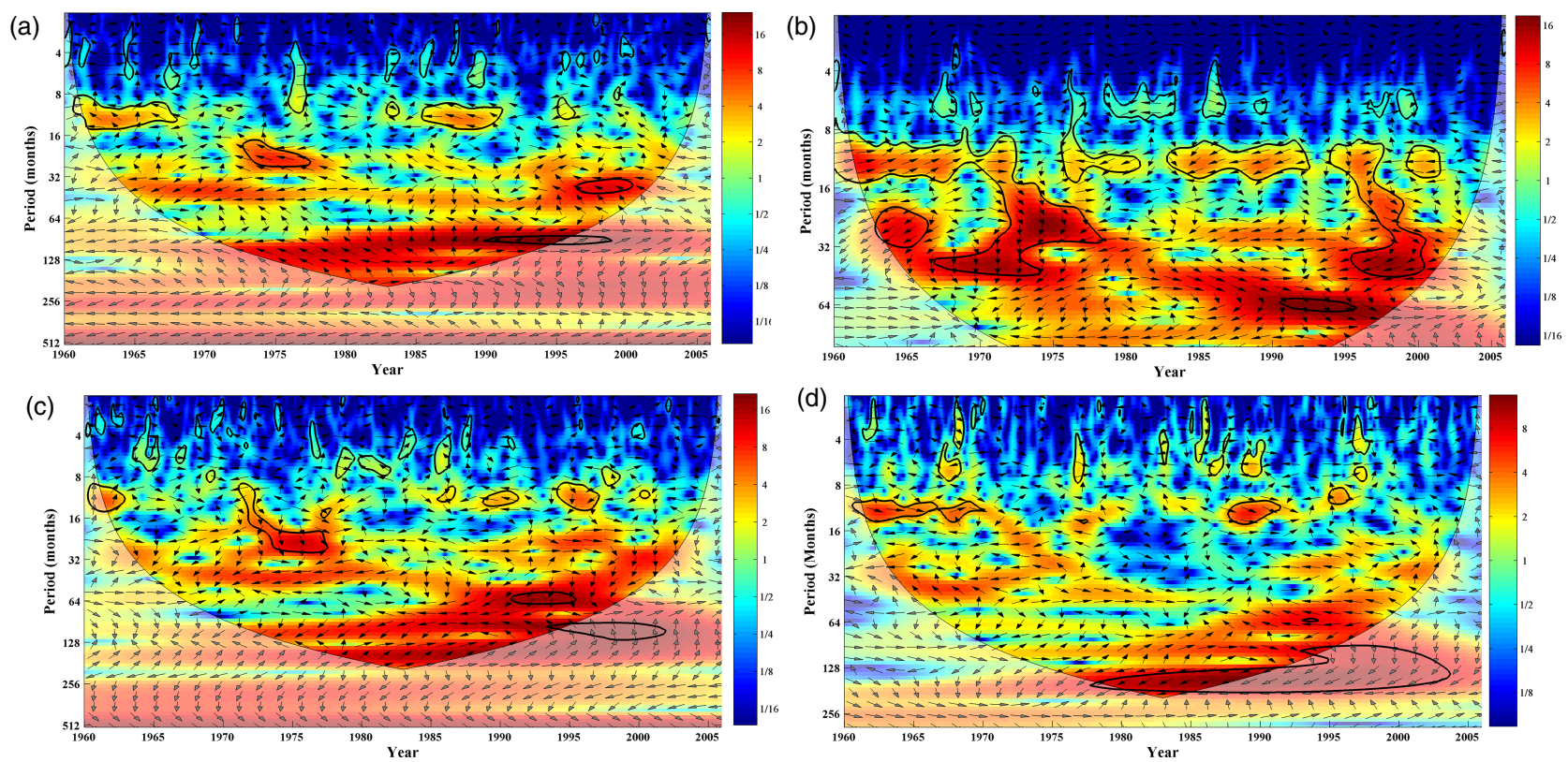

Figure 3. The cross-wavelet transforms between monthly SSI based on observed runoff and AMO (a), ENSO (b), PDO (c) and AO (d) indices covering 1960-2005 at the Dalles station, respectively. The 5\% significance level against red noise is exhibited as a thick contour, and the relative phase relationship is denoted as arrows (with anti-phase pointing left, in-phase pointing right).

index is leading SSI nearly 3 months. Overall, the impacts of ENSO on SSI are strong in 1960-1975 and 1991-2000 at Dalles station, while those in the rest periods are weak. It can be seen from Figure 3(d) that AO has a statistically negative correlation with SSI with a 120-200 month signal during 1978-2003. The mean phase of the significant regions is about $112^{\circ}$, implying that the AO index is leading SSI nearly 3.7 months. Generally, the influences of AO are strong in 1978-2003 at Dalles station, whilst those in the rest periods are weak. ENSO index mainly impacts SSI with a short period less than 10 years, while AO index primarily influences SSI with a long period more than 10 years. In general, among the four climate indices, ENSO index has the strongest influence on monthly SSI based on observed runoff at Dalles station. Similarly, the correlations between climate indices and monthly SSI based on observed runoff at Priest Rapids are similar to those at Dalles station. The relevant cross-wavelet analysis plots are omitted due to the limitation of space.

Figure 4 indicates that AMO has a weak influence on monthly SSI based on observed streamflow at Anatone station, whilst AO has the strongest impacts on SSI based on observed runoff with a 128-240 month signal during 1973-2004. The mean phase of the significant regions is about $135^{\circ}$, implying that the AO index is leading SSI nearly 4.5 months. Through visual comparison between
Figures 3(b) and 4(b), we can find that the influences of ENSO index on SSI based on observed streamflow at Anatone station is weaker than those at Dalles, implying that the impacts of ENSO on droughts in the Snake River are smaller than those in the main stream. Moreover, through visual comparison between Figures 3(d) and 4(d), we can find that the impacts of AO index on SSI at Anatone station are stronger than those at Dalles, indicating that the impacts of $\mathrm{AO}$ on droughts in the Snake River are stronger than those in the main stream. In addition, PDO passively mirrors SSI with a 128-200 month signal during 1980-2002 at Anatone station. The average phase of the significant region is about $315^{\circ}$, implying that the PDO index delays SSI nearly 1.5 months.

Through comparative analysis between Table 3 and the cross-wavelet analysis plots (Figures 3 and 4), we can find that the duration time of these worst droughts match well the time corresponding to the significant correlations between SSI and climate indices in the Columbia River basin. The droughts with severity of 12.37 and 12.3 at Dalles station and those with severity of 12.42 and 14.44 at Priest Rapids station are closely linked with ENSO index shown in Figure 3(b), whilst the rest worst drought events are closely associated with AO index exhibited Figures $3(\mathrm{~d})$ and $4(\mathrm{~d})$. The findings provide a reference to 
(a)

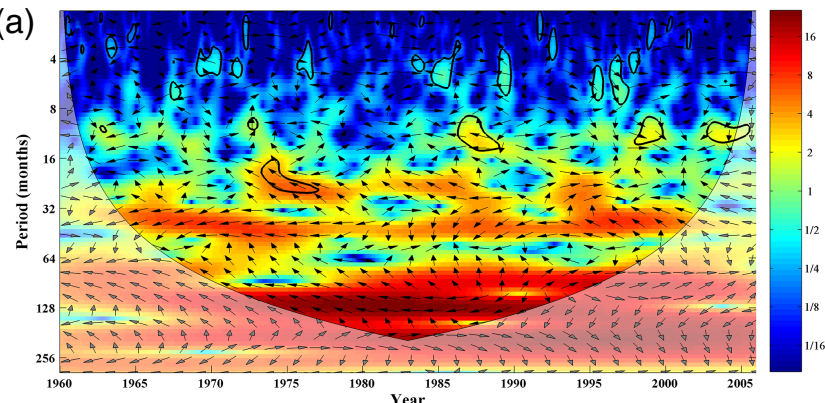

(c)

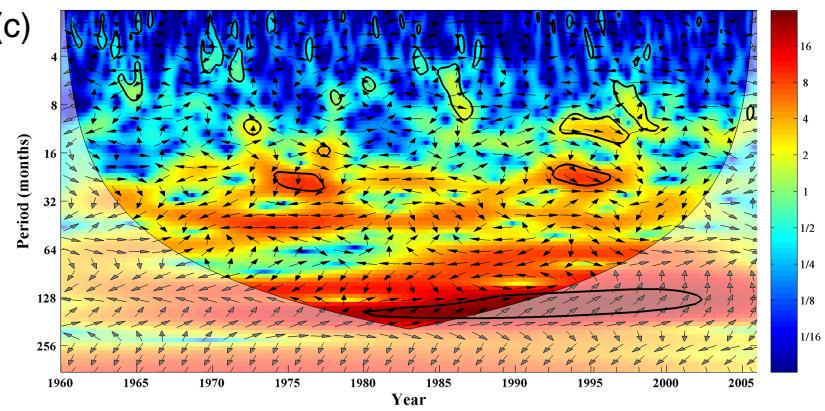

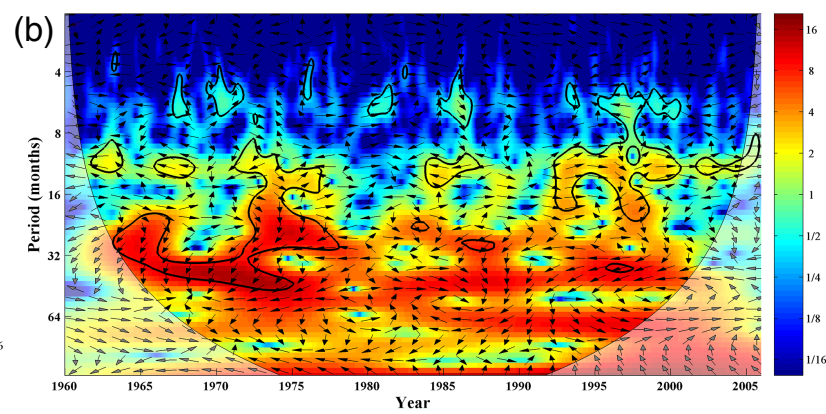

(d)

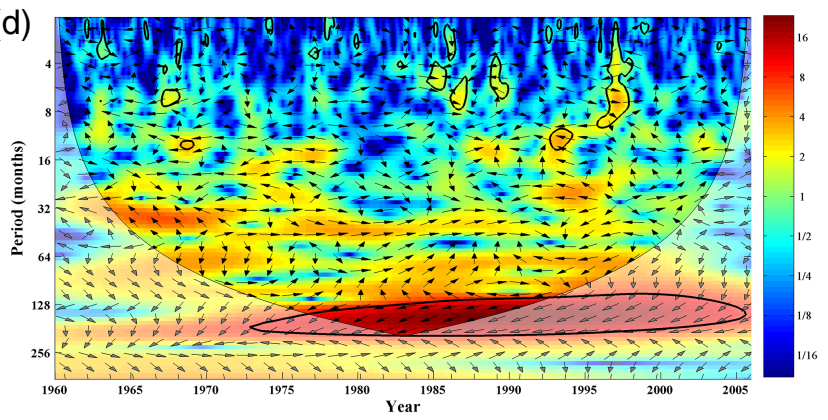

Figure 4. The cross-wavelet transforms between monthly SSI based on observed runoff and AMO (a), ENSO (b), PDO (c) and AO (d) indices covering 1960-2005 at the Anatone station, respectively.

find a direct correlation of droughts and climate indices in the cross-wavelet analysis plots.

Generally, among the four climate indices, ENSO and AO play a major role in impacting hydrological droughts in the Columbia River basin. The impacts of ENSO index on droughts in the main stream are stronger than $\mathrm{AO}$, whilst those are weaker than AO in the Snake River.

4.5. The impact of anthropogenic activities on the linkages between climate indices and hydrological drought

As the observed monthly streamflow data were applied to study the linkages between climate indices and hydrological drought, however, the intensifying human activities in the Columbia River basin such as water withdrawal, changes in land cover, reservoir regulation and so on may have some impacts on their correlations. Therefore, the naturalized streamflow data of Dalles, Anatone and Priest Rapids stations was used to investigate the influence of human activities on the links between climate indices and hydrological drought. As mentioned above, ENSO and AO indices play a major role in impacting hydrological droughts in the Columbia River basin. They are used to represent the major climate indices impacting local wet and dry condition. The cross-wavelet transforms between monthly SSI based on naturalized streamflow and ENSO and $\mathrm{AO}$ indices at Dalles station are exhibited in Figures 5 and 6 , respectively.

Through visual comparison between Figures 3(b) and 5 , we can obviously find that the significant correlations between SSI based on naturalized streamflow and ENSO at intra-annual scale (less than 12 months) are weaker than those based on observed streamflow, while those at inter-annual scale (more than 12 months) are similar to those based on observed streamflow. Similarly, through visual comparison between Figures 3(d) and 6, we can also find that the significant correlations between SSI based on naturalized streamflow and $\mathrm{AO}$ at intra-annual scale are weaker than those based on observed streamflow, while those at inter-annual scale are similar to those based on observed streamflow. Because human activities primarily affect the intra-annual characteristic of streamflow, whilst the correlation between climate indices and hydrological drought is mainly at inter-annual scale. Therefore, anthropogenic activities primarily impact the correlations between SSI and climate indices at intra-annual scale. Generally, the basic pattern of the correlations between climate indices and hydrological drought based on observed and naturalized monthly streamflow is similar. These findings at Dalles station are similar to Priest Rapids and Anatone stations, and their cross-wavelet analysis plots are omitted due to the limit of space. The results indicate that human activities primarily impact the correlations between SSI and climate indices at intra-annual scale. However, they do not change the basic pattern of the correlation between climate indices and hydrological drought. Therefore, human activities do not alter the basic pattern of the correlation between climate indices and hydrological drought in the Columbia River basin.

In order to further understand the detailed effect degree of anthropogenic activities on hydrologic droughts in the Columbia River basin, the statistical results of historical hydrological droughts based on naturalized runoff at the three stations are presented in Table 4 . Table 4 indicates that the number of the occurrence of moderate drought events based on the naturalized runoff at the three stations is 15 , which is a little bit smaller than that based on 


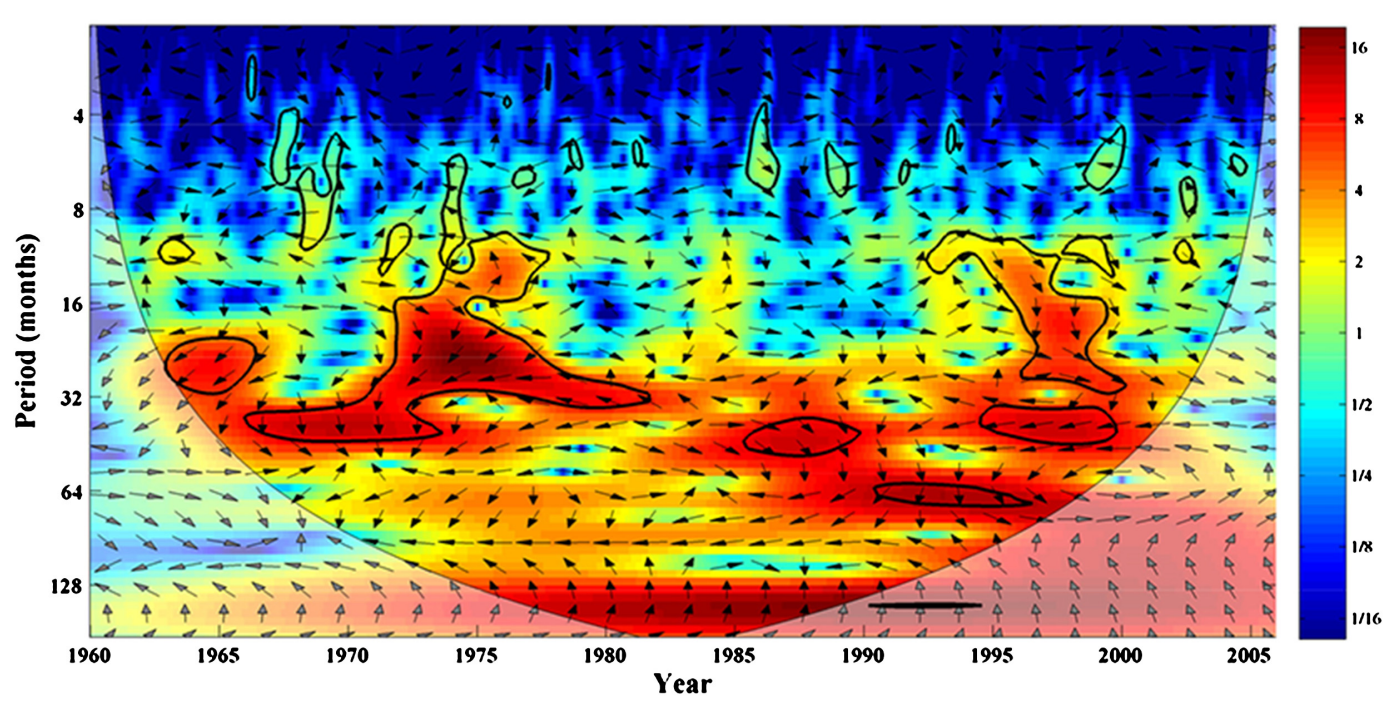

Figure 5. The cross-wavelet transforms between monthly SSI based on naturalized runoff and ENSO index covering 1960-2005 at the Dalles station.

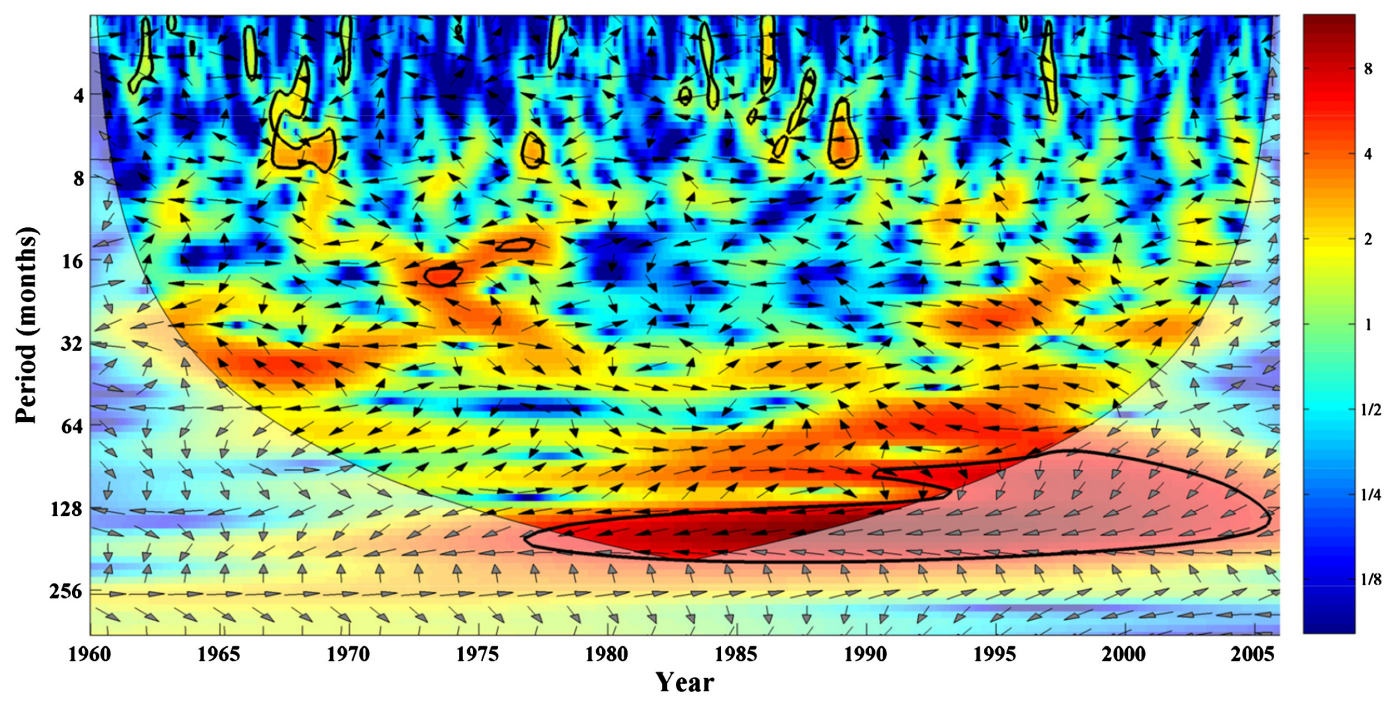

Figure 6. The cross-wavelet transforms between monthly SSI based on naturalized runoff and AO index covering 1960-2005 at the Dalles station.

observed runoff. Similar to Table 2, the total drought duration and severity at Anatone station are larger than Dalles and Priest Rapids stations. Through comparative analysis between Tables 2 and 3, we can find that the total drought severity based on naturalized streamflow at the three station decreases by 25.1, 24.9 and 9.8\%, respectively, compared with that based on observed runoff, while the total drought duration based on naturalized streamflow at the three station decreases by $24.0,22.4$ and $10.2 \%$, implying that anthropogenic activities are intensifying hydrological drought in the Columbia River basin.

\section{Discussions}

Bias correction is an important pre-processing procedure before the hydro-climate application of simulations due to unavoidable bias inherited from model structure, parameters, meteorological forcing and so on. There are various bias-correcting methods in hydro-climate applications such as the delta change factor and quantile mapping (Ho et al., 2012). The change factor which was derived from the mean monthly bias between simulations and observations was added or multiplied (depending on variables) to the observations. The quantile mapping method adopted in correcting the VIC simulations used in this study was performed through constructing the cumulative distribution function (CDF) of simulated and observed daily time series and then correct the CDF of simulations against that of observations at specific quantile bins. Through this approach, not only the mean but also the variability was maintained Haerter et al. (2011). However, a fundamental assumption has to be made in any of the bias-correction approach. That is, bias-correction algorithms are stationary (Maraun et al., 2010). Specifically, the bias between the simulations and observations for a specific time period was used to correct the simulations in other time periods. The other flaw in existing bias-correction methods is the inability to maintain the physical consistence between variables 
Table 4. The statistical results of historical hydrological droughts based on naturalized runoff at the three stations.

\begin{tabular}{|c|c|c|c|c|c|}
\hline \multicolumn{2}{|c|}{ Dalles } & \multicolumn{2}{|c|}{ Priest Rapids } & \multicolumn{2}{|c|}{ Anatone } \\
\hline Duration & Severity & Duration & Severity & Duration & Severity \\
\hline 3 & 3.44 & 3 & 3 & 6 & 8.61 \\
\hline 3 & 2.84 & 6 & 8.55 & 3 & 2.69 \\
\hline 6 & 8.93 & 3 & 4.09 & 7 & 7.93 \\
\hline 3 & 3.64 & 5 & 9.2 & 10 & 14.34 \\
\hline 10 & 15.7 & 3 & 3.07 & 4 & 4.12 \\
\hline 4 & 4.08 & 3 & 3.76 & 4 & 4.59 \\
\hline 3 & 3.38 & 3 & 2.94 & 18 & 25.96 \\
\hline 3 & 3.8 & 4 & 4.63 & 7 & 9.48 \\
\hline 5 & 6.82 & 3 & 5.15 & 3 & 4.02 \\
\hline 4 & 4.21 & 3 & 3.74 & 8 & 10.3 \\
\hline 4 & 5.03 & 5 & 5.91 & 3 & 2.84 \\
\hline 7 & 10.18 & 4 & 4.21 & 12 & 16.75 \\
\hline 12 & 18.91 & 5 & 7.93 & 4 & 4.47 \\
\hline 3 & 4.75 & 13 & 20.05 & 3 & 3.05 \\
\hline 3 & 3.27 & 3 & 3.7 & 5 & 6.22 \\
\hline \multicolumn{6}{|l|}{ Sum } \\
\hline 73 & 98.98 & 66 & 89.93 & 97 & 125.37 \\
\hline
\end{tabular}

because bias correction is performed for single variable for each time (Li et al., 2014). Moreover, the performance of bias correction is depending the time scales (Haerter et al., 2011). Therefore, it is important to bear in mind the above caveats of bias-correction method used in correcting the VIC simulations. To explore the uncertainties arising from the bias-correction method, however, is not within the scope of this study. Instead, our goal was to examine the relationship between hydrological droughts and climate indices with consideration of human impacts using the public dataset which has been widely used in various hydro-climate applications (e.g. Tesfa et al., 2014). Nevertheless, it is still interesting to use various bias-correction methods in correcting the VIC simulations to cover the uncertainty ranges and examine the sensitivity and robustness of our findings in the future.

\section{Conclusions}

It is of great importance to investigate linkages between hydrological drought and climate indices, which help to further understand the cause of hydrological drought from a perspective of climate change and guide future drought prediction and control. The Columbia River basin was selected as the study area in this study. The MMK trend test method was used to capture the trends of monthly SSI and annual runoff series spanning 1960-2012. The SSI was employed to characterize hydrological droughts. The heuristic segmentation method was applied to identify change points of annual streamflow series. Furthermore, the cross-wavelet analysis was utilized to analyse the correlations between monthly climate indices and SSI covering 1960-2005. The main conclusions are as follows:

1. The monthly SSI values have a statistically significantly increasing trend in November and December and a remarkably decreasing trend in June and July in the main stream of the Columbia River basin, while those in the Snake River have a statically significantly decreasing trend in January, February, October, November and December. In general, the SSI values in the Columbia River basin have a remarkable intra-annual variation characteristic.

2. No change points of annual streamflow series were identified at Dalles, Priest Rapids and Anatone stations in the Columbia River basin, implying that the hydrologic regime of the Columbia River basin keeps unchanged to a great extent.

3. The occurrence of moderate drought events at the three stations ranges from 16 to 18 during 1960-2005, implying that droughts frequently occur in the Columbia River basin. Overall, drought risk in the Snake River is larger than the main stream in the Columbia River.

4. Among the four climate indices, ENSO and AO play a major role in impacting hydrological droughts in the Columbia River basin. The impacts of ENSO index on droughts in the main stream are stronger than AO, whilst those in the Snake River are weaker than AO. Anthropogenic activities primarily impact the correlations between SSI and climate indices at intra-annual scale. However, they do not change the basic pattern of the correlations.

5. The total drought severity based on naturalized streamflow at Dalles, Priest Rapids and Anatone stations decreases by $25.1,24.9$ and $9.8 \%$, respectively, compared with that based on observed runoff, while the total drought duration based on naturalized streamflow at the three station decreases by 24.0, 22.4 and $10.2 \%$ compared with that based on observed runoff, implying that anthropogenic activities are intensifying hydrological drought in the Columbia River basin.

In general, this study thoroughly reveals the correlation between hydrological drought and climate indices. Note that considering anthropogenic activities on their linkages makes the findings obtained in this study solid. These findings are useful in guiding future drought prediction and mitigation in the Columbia River basin.

\section{Acknowledgements}

This research was supported by the National Major Fundamental Research Program (2011CB403306-2), the National Natural Fund Major Research Plan (51190093) and the Natural Science Foundation of China (51179148, 51179149 and 51309188), Water conservancy project special public welfare industry scientific research funds (201501058), the Key Innovation Group of Science and Technology of Shaanxi (2012KCT-10) and the China Scholarship Council. Sincere gratitude is extended to the editor and anonymous reviewers for their professional comments and corrections, which greatly improved the paper. 


\section{References}

American Meteorological Society (AMS). 2004. Statement on meteorological drought. Bull. Am. Meteorol. Soc. 85: 771-773.

Christensen OB, Christensen JH. 2004. Intensification of extreme European summer precipitation in a warmer climate. Glob. Planet Change 44: $107-117$

Dash MK, Pandey PC, Vyas NK, Turner J. 2013. Short communication variability in the ENSO-induced southern hemispheric circulation and Antarctic sea ice extent. Int. J. Climatol. 33: 778-783.

Daufresne M, Lengfellner K, Sommer U. 2009. Global warming benefits the small in aquatic ecosystems. Proc. Natl. Acad. Sci. USA 106(31): $12788-12793$

Flightner G. 2008. Natural streamflows: Columbia River tributaries in Washington, 1928-2006. Report of Gary Flightner Engineering to Washington Department of Ecology, Contract No. C0700334. http://www.hydro.washington.edu/2860 (accessed 10 April 2015).

Ghasemi R, Khalili D. 2006. The influence of the Arctic oscillation on winter temperatures in Iran. Theor. Appl. Climatol. 85: 149-164.

Grinsted A, Moore JC, Jevrejeva S. 2004. Application of the cross wavelet transform and wavelet coherence to geophysical time series. Nonlinear Processes Geophys. 11: 561-566.

Haerter JO, Hagemann S, Moseley C, Piani C. 2011. Climate model bias correction and the role of timescales. Hydrol. Earth Syst. Sci. 15: 1065-1079, doi: 10.5194/hess-15-1065-2011.

Hamed KH, Rao AR. 1998. A modified Mann-Kendall trend test for autocorrelated data. J. Hydrol. 204: 182-196.

Hamlet AF, Lee SY, Mickelson KEB, Elsner MM. 2010. Effects of projected climate change on energy supply and demand in the Pacific Northwest and Washington State. Clim. Change. 102(1-2): 103-128, doi: 10.1007/s10584-010-9857-y.

Hao ZC, AghaKouchak A. 2013. Multivariate standardized drought index: a parametric multi-index model. Adv. Water Resour. 57: 12-18.

Heim RR. 2002. A review of twentieth-century drought indices used in the United States. Bull. Am. Meteorol. Soc. 83: 1149-1165.

Henderson J, Kauffman N. 2012. Initial impacts of the 2012 drought. In The Main Street Economist: Agricultural and Rural Analysis, Vol. 3. Federal Reserve Bank of Kansas City: Kansas City, MO, 1-8.

Ho CK, Stephenson DB, Collins M, Ferro CAT, Brown SJ. 2012. Calibration strategies: a source of additional uncertainty in climate change projections. Bull. Am. Meteorol. Soc. 93: 21-26.

Hosking JRM. 1990. L-moments: analysis and estimation of distributions using linear combinations of order statistics. J. R. Stat. Soc. B 52(1): $105-124$

Huang SZ, Hou BB, Chang JX, Huang Q, Chen YT. 2014a. Copulas-based probabilistic characterization of the combination of dry and wet conditions in the Guanzhong Plain, China. J. Hydrol. 519: 3204-3213.

Huang SZ, Chang JX, Huang Q, Chen YT. 2014b. Spatio-temporal changes and frequency analysis of drought in the Wei River Basin, China. Water Resour. Manage. 28(10): 3095-3110.

Hudgins L, Huang JP. 1996. Bivariate wavelet analysis of Asia monsoon and ENSO. Adv. Atmos. Sci. 13(3): 299-312.

IPCC. 2007. Summary for Policymakers of Climate Change 2007: the Physical Science Basis. Contribution of Working Group I to the Fourth Assessment Report of the Intergovernmental Panel on Climate Change, Solomon S, Qin D, Manning M, Chen Z, Marguis M, Areryt KB, Tignor M, Miller HL (eds). Cambridge University Press: Cambridge. UK and New York, NY, 996 pp.

Kam J, Sheffield J, Wood EF. 2014. Changes in drought risk over the contiguous United States (1901-2012): the influence of the Pacific and Atlantic Oceans. Geophys. Res. Lett. 41: 5897-5903.

Kammerer JC. 1990. Largest rivers in the United States. US Geological Survey Open-File Report 87-242. http://water.usgs. gov/edu/riversofworld.html (accessed 10 April 2015).

Kunkel KE. 2003. North American trends in extreme precipitation. Nat. Hazards 29: 291-305.

Li S, Xiong LH, Dong LH, Zhang J. 2013. Effects of the three Gorges Reservoir on the hydrological droughts at the downstream Yichang station during 2003-2011. Hydrol. Processes 27: 3981-3993.

Li C, Sinha E, Horton DE, Diffenbaugh NS, Michalak AM. 2014. Joint bias correction of temperature and precipitation in climate model simulations. J. Geophys. Res. Atmos. 119(23): 153-162.

Li Z, Huang GH, Han JC, Fan Y, Cheng G, Zhang H, Huang W. 2015. Development of a stepwise-clustered hydrological inference model. J. Hydrol. Eng., doi: 10.1061/(ASCE)HE.1943-5584.0001165 04015008.

Ma ZZ, Wang ZJ, Xia T et al. 2014. Hydrograph-based hydrologic alteration assessment and its application to the Yellow River. J. Environ. Inform. 23(1): 1-13.

Maraun D, Wetterhall F, Ireson AM. 2010. Precipitation downscaling under climate change: recent developments to bridge the gap between dynamical models and the end user. Rev. Geophys. 48: RG3003.

Marcella MP, Eltahir EAB. 2008. The hydroclimatology of Kuwait: explaining the variability of rainfall at seasonal and interannual time scales. J. Hydrometeorol. 9(5): 1095-1105.

McKee TBN, Doesken J, Kleist J. 1993. The relationship of drought frequency and duration to time scales. In Eighth Conference on Applied Climatology, American Meteorological Society, Anaheim, CA, 179-184.

Menzel L, Bürger G. 2002. Climate change scenarios and runoff response in the Mulde catchment (Southern Elbe, Germany). J. Hydrol. 267: 53-64.

Mishra AK, Singh VP. 2010. A review of drought concepts. J. Hydrol 391: $202-216$

Mo K. 2010. Interdecadal modulation of the impact of ENSO on precipitation and temperature over the United States. J. Clim. 23: 3639-3656, doi: 10.1175/2010JCLI3553.1.

Modarres R. 2007. Streamflow drought time series forecasting. Stoch. Environ. Res. Risk Assess. 21: 223-233.

Naik PK, Jay DA. 2005. Estimation of Columbia River virgin flow: 1879 to 1928. Hydrol. Processes 19: 1807-1824.

Osorio JDG, Galiano SGG. 2012. Non-stationary analysis of dry spells in monsoon season of Senegal River Basin using data from Regional Climate Models (RCMs). J. Hydrol. 450-451: 82-92.

Pedro BG, Plamen CI, Amaral LAN. 2001. Scale invariance in the nonstation-arty of human heart rate. Phys. Rev. Lett. 87(16): 160815.

Roy SE, Balling JRC. 2004. Trends in extreme daily precipitation indices in India. Int. J. Climatol. 24: 457-466.

Sabziparvar AA, Mirmasoudi SH, Tabari H, Nazemosadat MJ, Maryanaji Z. 2011. ENSO teleconnection impacts on reference evapotranspiration variability in some warm climates of Iran. Int. J. Climatol. 31(11): 1710-1723.

Sadeghipour J, Dracup JA. 1985. Regional frequency analysis of hydrologic multiyear droughts. Water Resour. Bull. 21(3): 481-487.

Stahl K, Demuth S. 1999. Linking streamflow drought to the occurrence of atmospheric circulation patterns. Hydrol. Sci. J. 44(3): 467-482.

Stefan S, Ghioca M, Rimbu N et al. 2004. Study of meteorological and hydrological drought in southern Romania from observational data. Int. J. Climatol. 24: 871-881.

Talaee PH, Tabari H, Ardakani SS. 2014. Hydrological drought in the west of Iran and possible association with large-scale atmospheric circulation patterns. Hydrol. Processes 28: 764-773.

Tesfa TK, Li HY, Leung LR. 2014. A subbasin-based framework to represent land surface processes in an Earth system model. Geosci. Model Dev. 7: 947-963.

Torrence C, Compo GP. 1998. A practical guide to wavelet analysis. Bull. Am. Meteorol. Soc. 79: 61-78.

Vano JA, Scott VMN, Stöckle CO, Hamlet AF, Mickelson KEB, Elsner MM, Lettenmaier DP. 2010. Climate change impacts on water management and irrigated agriculture in the Yakima River basin, Washington, USA. Clim. Change. 102(1-2): 287-317, doi: 10.1007/s10584-010-9856-z.

Vasiliades L, Loukas A, Liberis N. 2011. A water balance derived drought index for Pinios River Basin, Greece. Water Resour. Manage. 25: $1087-1101$.

Vicente-Serrano SM. 2005. El Niño and La Niña influence on droughts at different timescales in the Iberian Peninsula. Water Resour. Res. 41: W12415, doi: 10.1029/2004WR003908.

Vicente-Serrano SM, López-Moreno JI, Beguería S, Lorenzo-Lacruz J, Azorin-Molina C, Morán-Tejeda E. 2012. Accurate computation of a streamflow drought index. J. Hydrol. Eng. 17: 318-332.

Wang WG, Shao QX, Yang T, Peng SZ, Yu ZB, Taylor J, Xing WQ, Zhao CP, Sun FC. 2013. Changes in daily temperature and precipitation extremes in the Yellow River Basin, China. Stoch. Environ. Res. Risk Assess. 27(2): 401-421.

Xu ZX, Takeuchi K, Ishidaira H. 2004. Correlation between El Niño-Southern Oscillation (ENSO) and precipitation in South-east Asia and the Pacific region. Hydrol. Processes 18: 107-123. 